\title{
Nitrite in Public Water-Supply Is a Health Hazard
}

\author{
Kenneth Hsu \\ Center of Health and Environmental Engineering, Kaifeng, China
}

Email address:

k.jinghwahsu@Gmail.com

\section{To cite this article:}

Kenneth Hsu. Nitrite in Public Water-Supply Is a Health Hazard. Science Journal of Public Health. Vol. 7, No. 1, 2019, pp. 25-30. doi: $10.11648 /$ j.sjph.20190701.14

Received: November 5, 2018; Accepted: November 22, 2018; Published: March 30, 2019

\begin{abstract}
The cancer cells are different from normal human body cells. The scientists advocating the Somatic Mutation Theory guessed that cancer is caused when mutations have caused the Human Genome of the human body-cells to change into the Cancer Genomes of the cancer cells. There is no evidence, however, indicating that there has ever been such a change, or that cancer cells have ever been human body cells. There is no evidence that the difference has resulted from changes, or mutations. Also there is no reason to assume that mutations of the Human Genome would cause the cancer cells to grow and replicate out of control. Chinese medical scientists have found, during the last half-century, a wealth of evidence that some forms of cancer may have been caused by the nitrite pollution of the public water supply. China's Deep Standardized Well Water (DSWW) Program of substituting nitrite-free deep groundwaters as the source of public water supply was partially successful. Local cancer-mortality rate was reduced by half at places where there is such a substitution. We found that cancer cells have inherited, not mutated, Cancer Genomes that encode uncontrolled growth and replication. In addition, PET scan studies have indicated that some cancer cells encode a metabolism of aerobic glycolysis under hypoxic conditions. Nitrite, as a reducing agent, could be the indispensable chemical in our food or drink intakes that could render the interior of cancer cells anaerobic. Nitrite, as an oxidation agent, could then be the substrate of the metabolic reaction anaerobic ammonium oxidation (anammox). A corollary of such a hypothesis is thus that cancer cells could be "starved" to death if there is no supply of nitrite to the cancer cells as a substrate of their metabolism. We recommend to the governments' National Health Services to look into this matter that nitrite in public water is a health hazard.
\end{abstract}

Keywords: Cancer, Cells, Mutation, Genome, Nitrite, Metabolism, Glycolysis, Anammox

\section{Introduction}

Cancer has been an enemy to the mankind ever since the antique time. With the ever-increasing environmental devastations, the cancer-incidence and mortality-rate have been increasing rapidly during the $20^{\text {th }}$ Century. In 2015 about $1 / 3$ of the population of UK have been afflicted by cancer. The current death rate is indeed alarming, about 9.5 million persons died of cancer each year Worldwide. The annual financial costs of fighting cancer were estimated to be more than 1 trillion US dollars.

Cancer is a group of diseases involving abnormal cellgrowth with the potential to invade or spread to other parts of the body. We have lost our loved ones through the incompetent conduct of the War on Cancer. With the recent conclusion of The Cancer Genomic Atlas (TCGA) studies, many are beginning to realize that the big mistake has been our blind faith in the Somatic Mutation Theory [1].

There is a wealth of evidence linking the origin of cancer to environmental degradation, such as the nitrite pollution of the public water supply [2]. A hypothesis was first proposed during the first post-war years, when the cancer-mortality rate of Japan deceased rapidly with the use of refrigeration, instead of nitrite, as meat-preservatives. The wealth of statistical evidence of questionable scientific significance led to an academic controversy, motivated in part by the fierce competitions for the cancer-research funding. The SMT scientists won, when the US Environmental Agency ended the controversy, rather arbitrarily, with their judgment that "nitrite is not carcinogenic." Nevertheless the statistics linking the cancer-mortality rate to the nitrite-concentration of drinking waters have continued to be Impressive [3-6]. Chinese scientists, working under conditions different from that of their colleagues in the West, carried out a large-scale clinical trial, namely the Standardized Deep Well-Water 
(SDWW) Program [7]. Surface waters, from streams, lakes, etc., in reservoirs are the normal sources of the public water supply. The SDWW comes from deep groundwater reservoirs, which are not polluted, as the depth of appreciable groundwater-pollution commonly is less than $300 \mathrm{~m}$. deep. The substitution of normal sources of water supply by SDWW has been a significant success. Where the substitution was made, the cancer-mortality rate was reduced by half. Scientists may continue to debate in their search for scientific explanations, but the fact remains that the SDWW has saved life.

The editors of all reputed science journals of the West had rejected Hsu's manuscript reporting the Chinese victories in the War On Cancer, before it was published by a new journal [7]. The article was ignored, while Hsu continued his search, as a gentleman scientist, to search for a scientific explanation of the link between cancer and nitrite. He came up with a surprise: Cancer could be, in many cases at least, considered an illness of chronic-poisoning by nitrite in public water supply. Rejected again by editors of reputed journals, Hsu's paper, co-authored with a geneticist R. Eckhardt, was published in the Chinese Journal of Geology [8]. If cancer is not caused by spontaneous mutations, we need to see the $4^{\text {th }}$, the temporal dimension to understand the evolution of Cancer Genomes. Cancer is a geological problem.

Yes, there are differences between cancer cells and human body cells. The advocators of the SMT have naively assumed the differences are manifestations of changes, and that the alleged changes have to be genetic mutations. They see no other alternative. Yes, the cancer cells are obviously different in their mode of growth: a single cancer cell would produce cells that start uncontrolled proliferation and replication. The SMT scientists have simply assumed this hallmark of cancer is that cancer cells are changed body cells that have been damaged by mutations. They could give no reason why mutations should encode such a mode of growth and replication. The SMT scientists have assumed that mutated genes have encoded the uncontrolled growth of cancer cells, when normal body cells were changed into cancer cells. The SMT scientists have assumed that such cancer cells have been changed to become the fittest as they are those that have survived. The SMT scientists have, however, not identified the "mutations" that should have definitely caused the growth of tumors. They have not told us how should the "mutations" have come about, or why should the "mutated cells" have grown and multiplied to form tumors. They have not identified the retroviruses that are supposedly to have caused the "mutations."

Great hopes were once placed on TCGA Project, which began in 2005 and ended a decade later. It was expected that a comparison of the sequence of normal DNA to those in different types of cancer cells could determine the exact "mutations" responsible for their origin. It was further hoped that a cataloguing of all such "mutations" that should have caused cancer would lead to the invention of drugs that targets those "driver mutations" to cure cancer. TCGA has turned out to be an "expensive disappointment" to the followers of the SMT. TCGA scientists did find random collections, but not orderly sequences of mutations. Furthermore the genomes of cancer cells, or the cancer genomes, are so different from the Human Genome that cancer cells are not likely to have originated from small "transcription errors" that are supposedly the mutations of the Human Genome of body cells. The SMT scientists cannot explain the genetics of cancer cells. They only speculated. We now believe that the cancer cells have never been healthy body cells.

The SMT scientists have incorrectly assumed that the alleged changes, or mutations, are caused by retroviruses. No mutations, no retroviruses can be assigned as definitely causative of cancer! They made a fundamental mistake when they took for granted that cancer cells were once body cells with the Human Genome. The Theory has little theoretical basis. All TCGA studies left no doubt that the cancer cells are descendents of cancerous stem cells. In essence, the SMT scientists were wrong when they simply assumed that the differences had resulted from changes, from mutations of the Human Genome. The Theory has nevertheless become a paradigm, and the mainstream opinion has been adopted as the scientific basis to fight the War On Cancer. It is thus not surprising that the War has been a failure.

Hsu and Eckhardt came to their interpretation because they recognized that differences are not necessarily manifestations of changes. The Cancer Cells are inherently different from the Human body-cells because the Cancer Cells have the Cancer Genomes, whereas the body-cells have the Human Genome. The two different types of genomes are inherently different. Cancer cells have inherited the Cancer Genomes from the cancerous stem-cells; Cancer Genomes are not mutations of the Human Genome. A hallmark of Cancer cells is their uncontrollable growth and replications. This hallmark of the Cancer genomes is not caused by mutations, or changes from the Human Genome. The growth of tumors is encoded by the inherited Cancer Genomes of Cancer cells, which, in the opinion of Hsu and Eckhardt, have evolved during, the last billion years or so, from an ancestral bacterial genome [8].

With their wrong postulate of random mutations, the SMT scientists could offer no prescription to stop the uncontrolled growth of tumors, except by killing off the tumor cells by chemo- or radiation therapies, or by removing the tumors with surgeries. At a more advanced stage, when metastasis has taken place, cancer cells spread through blood-circulation from one part to another part of the body. Tumors start to appear at unexpected sites, and are often discovered too late to be exterminated or removed. Terminal cancer is thus considered by the SMT scientists to be incurable. Those patients are sent to hospices, where treatment focuses on the patients' comforts rather on a cure, and the medication includes mainly drugs for pain management. That was a mistake. Terminal patients could be cured, if we have correctly understood the origin of cancer. 


\section{New Strategy and New Tactics to Fight the War on Cancer}

The essence of the Cancerous Stem Cell Theory of Hsu and Eckhardt is the postulate that the inherited Cancer Genomes, not mutations, make the cancer cells different [8]. The Cancer Genomes encode the uncontrolled growth and replications. The Cancer Genomes also encode the metabolic reactions that are different from those encoded by the Human Genome.

Metabolism is the set of life-sustaining chemical transformations within the cells of living organisms. The three main purposes of metabolism are the conversion of food/fuel to energy to run cellular processes, the conversion of food/fuel to building blocks for proteins, lipids, nucleic acids, \& some carbohydrates, and the elimination of nitrogenous wastes. These enzyme-catalyzed reactions allow organisms to grow and reproduce, while maintaining their structures, and with changes in response to their environments. The word metabolism can also refer to the sum of all chemical reactions that occur in living organisms, including digestion and the transport of substances into and between different cells.

Metabolism is usually divided into two categories: catabolism, the breaking-down of organic matter for example, the breaking down of glucose to pyruvate, by cellular respiration, and anabolism, the building-up of components of cells such as proteins and nucleic acids. Usually, breaking-down releases energy and building-up consumes energy. The chemical reactions of metabolism are organized into metabolic pathways, in which one chemical is transformed through a series of steps into another chemical, by a sequence of enzymes. The metabolic system of a particular organism determines which substances are "nutritious" and which are "poisonous." For example, some prokaryotes use hydrogen sulphide as a nutrient, yet this gas is poisonous to animals. The metabolic rate influences how much food an organism will require, and also affects how it is able to obtain that food. A striking feature of metabolism is the similarity of the basic metabolic pathways and components between vastly different species.

The metabolism of eukaryotes includes glycolysis, citricacid cycle, and oxidative phosphorilation (OXPHOS). Glycolysis, a most primitive form of metabolism by the prokaryotes, takes place in cytoplasm. The citric-acid cycle occurs in the mitochondrial matrix, and the OXPHOS metabolism occurs at the internal folded mitochondrial membranes. The different modes of metabolism of cancer cells give the evidence of an evolutionary history of the metabolism from the prokaryotes to the eukaryotes, in response to a change of the increasingly oxygenated atmosphere.

Cancer was first suspected as a metabolic disease when Warburg postulated that the origin of cancer could be related to oxidative metabolic reactions under reducing conditions [9]. Hsu and others recognized a possible double role of nitrite [7]. Nitrite as a reducing agent could render the interior of a cell oxygen-deficient. Nitrite, as an oxidizing agent, could be the substrate of oxidizing metabolic reactions such ammonium-oxidation metabolism by nitrite (anammox). They postulated that the ancestral Cancer Genomes may have evolved from a bacterial Anammox Genome so that they could encode, in addition to uncontrolled growth and replications, also anammox metabolism [7]!

As a geologist studying biologic evolution in response to the changing atmospheric environment of the Earth, Hsu applied the Lynn Margulis theory [10]! on the origin of eukaryotes to explain the origin of cancer. He postulate that

(1) The Cancer Genomes have evolved from the Annamox Genome of a Precambrian anammox bacterium.

(2) The Anammox Genome was acquired by a Precambrian cyanobacterium. The cyanobacteria had first invented photosynthesis more than 1 billion years ago.

(3) Anaerobic bacteria seeking refuge in anaerobic environments when the Earth's atmosphere became increasingly oxygenated, because the release of oxygen to the atmosphere by the photosynthetic bacteria.

(4) An anammox bacterium found refuge in the anaerobic interior of a photosynthetic cyanobacterium.

(5) The symbiogenesis of the two formed the first eukaryote some 1 billion years ago.

(6) The body of evolving eukaryotes always had two genomes in parallel evolution at different rates.

(7) The Cyanobacterium Genome rapidly evolved into that of single-celled eukaryote, into fungi, plants and animals, while the Anammox Genome evolved, at a relatively slow rate, into the Cancer Genomes of the Cancer cells now found in the body of various eukaryotes such as H. sapiens. The Cancer Genomes are responsible for the two hallmarks of cancer cells: the uncontrolled growth and replication of cells and a metabolism mode different from the oxidative phosphorilation (OXPHOS), which is common to all eukaryotes.

(8) Cancerous stem cells "hibernate" when the condition of the cell interior does not permit anoxic or hypoxic metabolism, or when there is no supply of a substrate to sustain such metabolic reactions.

(9) The presence of nitrite in drinking water, which is diffused into cancer cells, could create a condition suitable for aerobic glycolysis under hypoxic or for anammox under anoxic conditions.

(10) Nitrite plays a double role, as a reducing agent to render the cell interior hypoxic or anoxic, as an oxidizing agent for metabolic reactions, such as in anammox, by cancer cells.

(11) Therefore, cancer cells which cannot survive when they are deprived of oxygen may be considered to have been "choked," or "starved," to death.

(12) Use of nitrite-free waters, such as the Sulan Water, as an anti-cancer substance in chemotherapy can "starve" the cancel cells to death, but they do not harm normal body cells. 


\section{Random Clinical Experiments}

With a new understanding of the Origin of Cancer, we have a new insight into the functions of tumor suppressors. The SMT scientists postulated that alterations of the protein p53 are involved in nearly half of all cancer cells, and its nuclear role is to regulatory the shift from OXPHOS to the glycolytic pathway of metabolism. The SMT further postulated that transcription factors that are activated by cellular stresses or "DNA damages by somatic mutations" that trigger enzymes and pathways leading to the activation of tumor-suppression genes. They would thus arrest the growth of tumour cells. With our new understanding of the role metabolism in carcinogenesis, we may offer a different interpretation of the important $\mathrm{p} 53$ protein. In our experiments culturing cancer cells with nitrite-rich solutions, we found a remarkable abundance of p53 in the solution. The abundance is consistent with our postulate that the metabolic mode of metabolism had been shifted by the p53 to suppress the growth of human body cells by OXPHOS. Therefore, a suppression of the p53, which promotes glycolysis metabolism of cancer cells, should lead to a suppression of tumor-growth.

Our CSC hypothesis on the origin of cancer is to be further tested by experiments. All living organisms depend upon metabolism to digest food and to store vital energy in the ATP. The metabolic processes are oxidation processes carried out under oxidative, hypoxic, or anoxic environment. Without metabolism to produce and to store the vital energy, a living organism cannot grow. When cancer cells cannot grow, tumors shrink in size. The change in tumor size could be observed and monitored, when cancer cells are being "starved" to death. The hypothesis thus predicts that the presence of nitrite in solutions culturing cancer cells favour the growth of tumors, and they should increase their size. The hypothesis also predicts that the absence of nitrite should favour the growth of body cells and suppress the growth of tumors, and their size should shrink. The predictions depend upon a recognition that the mode of metabolism of growing cancer cells is anammox by nitrite.

Hsu pilot studies have only searched for an explanation of the statistical link between cancer and nitrite [7]. PET scans may yet prove that some cancer cells may have the metabolic mode of anammox. Meanwhile, our friends sympathetic to our viewpoints have voluntarily performed an easy experiment through the substitution of normal tape-water as drinking water by nitrite-free pure-clean water. A person need to drink about a liter of water per day. There is no law to prohibit a physician to prescribe pure clean water as the drinking water for his patients, so that one does not have to go through the difficult procedures of testing the efficacy of a new medicine by a clinical trial. We could start, and nobody could object, that we use purer and cleaner water as our drinking water in order to test whether pure-clean water is a good "medicine" to suppress the growth of cancer, without having to go through the very complicated procedures of applying a clinical trial to test a new medicine.
Hsu had this idea that nitrite-free water could cure cancer, and I tried to give talks but I was retired from the University, and nobody would give me a chance to give a lecture. Once an American friend FD came to visit me, and I talked to him about my new hypothesis. He was a chemist and he understood the chemistry of metabolism. Furthermore, his wife had just started to have a cancer-growth in her mouth. It was very painful and her husband would do anything to relieve her of the severe pain. Their son was a chemical engineer. He set up a distillation apparatus at home, so that Mrs. FD could drink distilled water, a liter a day. Miraculously, tumours decreased in size, and the cancer was going away when she received a notice from the hospital, where she was waiting for a hospital bed to undergo a surgery. So they went to enrol in the hospital, one of the best cancer hospitals of the World. At the admission office, FD made a request that his wife could continue to drink her distilled water. His request was denied by the Director. When FD mentioned that the hypothesis was formulated by his Chinese friend. The racist Director made a disparaging remark that "Chinese Science was second rate." FD was in the $14^{\text {th }}$ Air Force in China and was a great friend of the Chinese. Hsu was so incensed by the racist remark, that he punched the Director in the face. Hsu was held back, of course, and the Director was telling his underlings to call the police. At that moment, Mrs. FD interrupted the proceedings, and said:

"FD, never mind. I do not really think that it matters that much what water I should drink. We should follow the rules of the hospital, and drink the water that they give me."

So she was admitted into the hospital, and followed the rules. Soon the tumours in her mouth came back. After 3 months, she could neither speak, or eat, or even dare to open her mouth. She died of cancer.

A few years later, Hsu talked to a friend CMP of Taipeh, who had changed his profession from a Professor of Geology to a Minister of a Christian Church. CMP had always respected my "crazy ideas," and he also believed that if a person has discovered a way to cure cancer without deleterious side-effects, he should be given a chance to express his harmless opinions. So he told me that I could give a lecture at his church. One of the congregation-members of his church was a daughter-in-law of a richest person in Taiwan. If Hsu could save her life, was told, there would be enough publicity when everybody would believe in me. I was not to miss the opportunity. So Hsu asked CMP to schedule a lecture when Hsu visited Taiwan again the next year. Hsu was reluctant, because the daughter-in-law had died of cancer, but he gave in and Hsu could give a talk to an audience of a dozen or two. Hsu could not help but mentioned the tragedy of Mrs. FD.

A few months after my talk, Hsu got an email from CMP, who told Hsu that a miracle had happened. The husband of a lady in his congregation was a retiring Director of the TriServices Hospital at Taiwan. He had terminal cancer, and was entering his own hospital for a last chemotherapy. The wife remembered my talk, and she also remembered my story. She 
bought from a supermarket some bottles of nitrite-free pureclean water, and took the bottles to the hospital for her husband. She remarked that the tape-water does not taste as good as the spring water. Her husband drank 1 liter a day. $\mathrm{He}$ was feeling better all the time. After three months, he had a final examination and was told that his tumours were almost all gone. They could operate on him, and so they did. So the husband was cured. But the operation did not eliminate the last cancer cells. When the husband started to consume again public water-supply, his cancer came back. So he knew that he had to drink nitrite-free water until the last day of his life. I saw him a few years ago. He was in good health, and in good spirit. He is still doing that. So the Director of the TriServices Hospital is a terminal patient who has survived.

CMP recommended a second cancer patient to the TriServices Hospital. The attending physician took the matter very seriously. The patient drank 1 liter a day of the nitritefree water. She was examined every month by X-ray. Her tumours all shrank in size, at the rate by $1 / 3$ every month. So the patient was again cured after 3 months. Better still, the hospital has now a medical record of her convalescence.

The third patient of the Tri-Services Hospital was the wife of CMP. She entered the terminal stage, and tumours grew everywhere including growths in her lungs. Drinking the nitrite-free water, she was almost cured after three months, except the tumors in the lungs. The explanation was simple, there is too much nitrite in the air. The CMPs went to New Zealand where they could have clean air. After 3 months, they came back. She went to the hospital, and they found that her lung cancer was also gone.

After those three "successes stories," Hsu was hoping that the medical establishment would take him seriously. Yes, there are a few friends who are interested, but the medical establishment considered a crazy idea of a geologist cannot cure cancer. So, nothing is done. Furthermore, Hsu could not even publish the manuscript of his scientific hypothesis, until a young editor of the Chinese Journal of Geology found no reasons to reject his manuscript. The young man accepted the manuscript for publication after 5 of the peer-reviewers wrote very positive evaluation. The boss, the Editor in Chief, wrote an editorial to justify the editorial decision. That was 2 years ago. Meanwhile, millions are dying of cancer each year, but the medical establishment still does not accept Hsu"s "crazy idea."

Hsu did persuade three physicians to carry out experiments in the treatment of 3 terminal cancer patients: Our CSCT predicts that cancer should be cured if a patient consumes, 1 liter per day, "pure clean" water with a MPCL of $0.002 \mathrm{mg} / 1$ nitrite-N. The theory also predicts that cured cancer patients may have a relapse if they should again drink nitrite-polluted water. Our 3 experiments have verified the 3 predictions: Cancer patients drinking 1 litre per day of "nitrite-free" water in 100 days were cured. Cured patients drinking again nitritepolluted public water-supply all began to have a relapse The shrinkage of tumors of one patient was observed and monitored with X-ray photographs by the attending physician at the Tri-Services Hospital of Taipeh. The tumor shrank at a rate of 1/3-reduction of tumor-size each month. The terminal patient was on her way of full recovery after 3 months. Now there is a $\mathrm{n}$ method to cure cancer, if it is indeed an illness of chronic nitrite-poisoning. The Hsu/Eckahrdt prescription of drinking 1 liter of nitrite-free pure clean water each day for 100 days to cure cancer can be considered a form of a chemotherapy. The usual anti-cancer drugs used in chemical therapy are toxic to healthy body cells, but the pure-clean water is not. The advantage of using such water is verified by Hsu's three hospital trials, by China's DSWW Program, and also by the experiences of the Hsu-Village where no permanent resident ever died out cancer. People there have been drinking nitrite-free pure-clean waters there for thousands of years, and there have not been any deleterious consequences to health that could be attributed to the waters.

With the terminal cancer patients dying every 5 seconds, Hsu proposed that all cancer hospital and hospices should immediately use nitrite-free pure clean waters as potable water. He also proposed that the Government consider the organization of Sulan Health Service for Cancer Patients to better our understanding of the origin of cancer and to better our practice of curing cancer. He further proposed to the PRC Government that a systematic clinical trials be immediately carried out. The governments have an obligation to answer the question Is nitrite in current public water-supplies a health hazard?

\section{Conclusion}

The interpretation that cancer has not resulted from somatic mutations of the Human Genome of human bodycells has far-reaching significance in searching for a cure of cancer. The Cancer Cells have never been human body-cells. The Cancer Cells grow because the cells have not inherited the Human Genome; they have inherited the Cancer Genomes. Cells are the basic element of all living biologic organisms. Each type of cells is characterized by their specific genome. Human body cells have the Human Genome. Cancer Cells have the Cancer Genomes, and Human Cells have the Human Genome. Each of the two types of cells has their distinctive mode of metabolism and distinctive mode of growth and replication different mode. In chemical therapies we search for chemical substances which would kill the cancer cells, but not the Human body cells. Knowing their different modes of metabolism gives us a new procedure and a new medication to treat cancer. When cancer cells are deprived of nourishment, they would be "starved" to death. Now we have the explanation of the link of cancer and nitrite. If the metabolic mode of some types of cancer cells is anaerobic ammonium-oxidation (anammox), nitrite is the substrate that sustains the metabolic reaction. Nitrite in food is oxidized into nitrate, and becomes harmless after food is digested by gastric acid in the stomach. Nitrite in drinking water, like drinking-alcohol in empty stomach, would not be changed into nitrate; it would go directly into the blood stream, where nitrite is carried by circulating blood stream to feed the cancer cells. Cancer cells which have the anammox 
metabolism would be starved to death when there is no nitrite in drinking water.

PET scans have shown other modes of metabolisms in other types of cancers. The sources of oxygen for the metabolism of prokaryotes, such as sulphate-reduction and anammox bacteria, utilizing oxygen in sulphates or in nitrite. The oxygen for the fermentation by yeasts or for glycolysis comes from carbohydrates. It is therefore not surprising that alternative cancer-hospitals include those which have a sugar-free, a starch-free diet to cure the patients.

If our theory that cancer cells could be starved to death, a routine examination of cancer patients should include, first of all, PET scans to determine the metabolic mode of the cancer cells of a patient. If the anammox is the metabolism, the patients should drink nitrite-free water. If aerobic glycolysis is the metabolism, the patients should have a diet free of carbo-hydrates. Deprived of nourishment, cancer cells die and tumors shrink in size, at a rate of about $1 / 3$ per month. The size of the tumors should be smaller enough so that surgery could remove the last traces of the cancer cells.

\section{Acknowledgements}

The idea that cancer could be caused by nitrite pollution was another one of "Ken Hsu's crazy ideas." He is indebted to many colleagues for their inspiration and encouragement during his long journeys since 2005. First of all, it was fortunate that the late Lynn Margulis was a guest professor at the Oxford University, when she taught Hsu her theory of biologic evolution by acquisition of genomes during symbiogenesis. Hsu was also much indebted to his daughter Elisabeth Hsu and his former students at the Swiss Institute of Aquatic Science (Dubenbdorf) who introduced to him the idea that nitrite may have played a role in initiating the anammox metabolism of cancer cells. Hsu is grateful to the People's Government of the Anhui Province for giving me a chance to discuss the possibility of using nitrite-free water to cure cancer. I am indebted to Dr. Zhang Wei of the Chinese Journal of Geology, who was the one editor, a Chinese, who has the vision to see that cancer is a problem of biologic evolution in geology, an adaptation of metabolic mode of living organisms to the ever-increasing oxygenation of the Earth's atmosphere.

\section{References}

[1] H. Ledford, End of cancer-genome project prompts rethink. Nature 2015, 517, issue 7533.

[2] Z. X. Xu, Chemical fertilizers, sewage treatment, and aesophyageal cancer (in Chinese). Scientific publishers, Beijing, 2003, 257 pp.

[3] D. C., Paik, D. V. Saborio, R. Oropeza, and H. P. Freeman, The epidemical enigma of gastric cancer rates in the United States. Int. Jour. Epidemiology 2001, 30, 181-182.

[4] Y. Kitamura, T. I, memura, K. Okazaki, et al. Enhanced effects of simultaneous treatment with sodium nitrite on 2-amino-3methylimidazo quinoline induced rat-liver, colon, and Zymbal's gland carcinogenesis after initiation with Diethylnitrosamine and and 1,2-Diethylhydrazine. Int. Jour. Cancer, 2006, 118, 2399-2404.

[5] T. H. Tseng, M. C. Chang, J. D. Hsu, et al. Tumor promoting effect of N-nitroso-, N-2-hexanony in Benzoa Pyrene-Initiated Mouse Skin Carcinogenesis. Chemico-Biological Inferactions.

[6] H. Tsuda and H. Hasegawa. Malignant transformation of mouse BALB/c3T3 cells induced by $\mathrm{NaNO}_{2}$, Carcinovgenesis 1990, 11, 595-597.

[7] Hsu K. J., Huangfu C. S., Qin, M. Z. Role of nitrite in tumor growth, symbiogenetic evolution of cancer cells, and China's successes in the War against Cancer. J Cancer Therapy 2011, 2: 601- 606 .

[8] Hsu, K. J. and Eckhardt, R. Origin and cure of cancer. Chinese Jour. Geology, 2016, 51 (4): 1-33.

[9] Warburg, O. On the origin of cancer cells. Science 1956, 123: 309-314.

[10] Margulis Lynn (formerly Sagan, Lynn). On the origin of mitosing cells". Journal of Theoretical Biology, 1967 14: 225274. 